\title{
Identification and Characterization of Circular Intronic RNAs Derived from Insulin Gene
}

\author{
Debojyoti Das ${ }^{1,2,+}$, Aniruddha Das ${ }^{1,2,+}$, Mousumi Sahu ${ }^{1}$, Smruti Sambhav Mishra ${ }^{1}$, \\ Shaheerah Khan ${ }^{1}$, Pruthvi R. Bejugam ${ }^{1}$ (D), Pranita K. Rout ${ }^{1}$, Arundhati Das 1,2, \\ Shehnaz Bano ${ }^{3}{ }^{(D}$, Gyan Prakash Mishra ${ }^{1}$ (D), Sunil K. Raghav ${ }^{1}$, Anshuman Dixit ${ }^{1}$ (D) and \\ Amaresh C. Panda ${ }^{1, * \mathbb{D}}$ \\ 1 Institute of Life Sciences (ILS), Nalco Square, Bhubaneswar, Odisha 751023, India; \\ debojyotidas.phy@gmail.com (D.D.); ani.geneinvo@gmail.com (A.D.); \\ mousumi.nina.sahu1@gmail.com (M.S.); sambhubioinfo@gmail.com (S.S.M.); \\ khshaheerah@gmail.com (S.K.); raj.pruthvi@gmail.com (P.R.B.); pranita.liza.09@gmail.com (P.K.R.); \\ arundhati.das12345@gmail.com (A.D.); j12mishra@gmail.com (G.P.M.); \\ raghuvanshi2010@yahoo.co.in (S.K.R.); anshumandixit@gmail.com (A.D.) \\ 2 School of Biotechnology, KIIT University, Bhubaneswar, Odisha 751024, India \\ 3 National Center for Cell Sciences (NCCS), Pune, Maharashtra 411007, India; sbs90786@gmail.com \\ * Correspondence: amaresh.panda@ils.res.in; Tel.: +91-674-230-43-14 \\ + Contributed equally to this work.
}

Received: 21 April 2020; Accepted: 9 June 2020; Published: 17 June 2020

\begin{abstract}
Circular RNAs (circRNAs) are a large family of noncoding RNAs that have emerged as novel regulators of gene expression. However, little is known about the function of circRNAs in pancreatic $\beta$-cells. Here, transcriptomic analysis of mice pancreatic islet RNA-sequencing data identified 77 differentially expressed circRNAs between mice fed with a normal diet and a high-fat diet. Surprisingly, multiple circRNAs were derived from the intron 2 of the preproinsulin 2 (Ins2) gene and are termed as circular intronic (ci)-Ins2. The expression of ci-Ins2 transcripts in mouse pancreatic islets, and $\beta$ TC6 cells were confirmed by reverse transcription PCR, DNA sequencing, and RNase R treatment experiments. The level of $c i$-Ins 2 was altered in $\beta$ TC6 cells upon exposure to elevated levels of palmitate and glucose. Computational analysis predicted the interaction of several RNA-binding proteins with ci-Ins2 and their flanking region, suggesting their role in the ci-Ins2 function or biogenesis. Additionally, bioinformatics analysis predicted the association of several microRNAs with ci-Ins2. Gene ontology and pathway analysis of genes targeted by miRNAs associated with ci-Ins2 suggested the regulation of several key biological processes. Together, our findings indicate that differential expression of circRNAs, especially ci-Ins 2 transcripts, may regulate $\beta$-cell function and may play a critical role in the development of diabetes.
\end{abstract}

Keywords: pancreatic $\beta$-cells; lariat-derived circRNA; insulin splicing; translation; diabetes

\section{Introduction}

Diabetes is one of the most common diseases in the world [1]. Diabetes is characterized by increased blood glucose levels due to the dysfunctional sensing or production of insulin [2,3]. Pancreatic $\beta$-cells synthesize and secrete insulin to maintain glucose homeostasis in the body [4]. The biosynthesis and secretion of insulin from $\beta$-cells require tight regulation of gene expression at transcriptional as well as at post-transcriptional level [5-7]. It has been well established that transcription factors, RNA-binding proteins (RBPs), long noncoding (lnc)RNAs, and micro (mi)RNAs regulate insulin synthesis and secretion from $\beta$-cells [5-9]. In recent years, another class of ncRNA called circular RNA (circRNA) has emerged as a critical regulator of gene expression [10]. 
High-throughput RNA-sequencing (RNA-seq) has led to genome-wide annotation of circRNAs in a variety of organisms, including humans [11-13]. The majority of circRNAs are generated by the backsplicing of pre-mRNAs, whereby a downstream splice site covalently joins with an upstream splice site [13-15]. Additionally, some intronic lariats escape the debranching process during splicing and generate stable circular intronic (ci)RNAs [16]. CircRNAs are categorized into various types based on their sequence composition, such as exonic circRNA, exon-intron circRNA (EIciRNA), and circular intronic RNA (ciRNA) [13,16-18]. CircRNAs are resistant to exonucleases and are much more stable than the linear RNAs due to lack of free ends $[19,20]$. Recently, circRNAs have been reported to regulate gene expression by sponging miRNAs and RBPs, and by producing peptides [21-24]. Although the molecular mechanisms for the majority of the circRNAs are unknown, they have indeed been implicated as regulators of crucial cellular events, including signaling, proliferation, apoptosis, differentiation, and aging $[23,25,26]$. Furthermore, altered expression and function of circRNAs have been reported in various pathological conditions, including cancer, diabetes, Alzheimer's disease, neurodegeneration, and muscle degeneration [27-32]. However, the function of circRNAs in $\beta$-cell physiology and the development of diabetes is not well studied.

In this study, we wanted to identify circRNAs expressed in pancreatic islets of a diabetes mice model and to investigate their role in $\beta$-cell physiology. Here, we used previously published RNA-seq data on pancreatic islets of a type 2 diabetes mouse model to identify the expression pattern of circRNAs. This comprehensive analysis of circRNAs with CIRCexplorer2 and CIRI2 identified thousands of circRNAs, and several circRNAs were found to alter their expression in the islets of mice fed with a high-fat diet (HFD) compared to a normal diet (ND). Interestingly, several circRNAs were found to be derived from the preproinsulin 2 (Ins2) gene. Furthermore, we validated the expression of ci-Ins2 in mouse pancreatic islets and $\beta$ TC 6 cells. A computational analysis suggested that $c i-I n s 2$ transcripts might sponge several RNA-binding proteins (RBPs) and microRNAs. Together, our findings provide the first example of circular transcripts generated from the insulin gene and their potential to regulate $\beta$-cell physiology.

\section{Results}

\subsection{Identification and Characterization of Pancreatic Islet CircRNAs}

To conduct the genome-wide identification of circRNAs in pancreatic islets, we retrieved publicly available RNA-seq data sets from pancreatic islets of mice fed with ND or HFD [33]. A total of 67,146 and 28,903 circRNAs were identified with circRNA annotation algorithms CIRCexplorer2 and CIRI2, respectively (Figure 1A,B). The vast majority of the circRNAs identified with CIRI2 and CIRCexplorer2 were derived from exonic sequences, while only about $10 \%$ of the circRNAs originated from intronic or intergenic regions. Since the majority of the circRNAs identified by CIRI2 were also identified in CIRCexplorer2 and the total number of identified circRNAs were significantly higher in CIRCexplorer2 annotation (Figure 1B, Tables S2 and S3), we used the CIRCexplorer2 data for further characterization of circRNAs.

Approximately half of the circRNAs identified with CIRCexplorer2 were exclusively expressed either in ND or in HFD samples (Figure 1B). The mature spliced length of identified circRNAs range from less than a hundred to several thousand nucleotide long, and the majority of the circRNAs were found to be less than 2000 nucleotides (Figure 1C). Although the number of exons incorporated in the exonic circRNAs varied from 1 to 56, the majority of them consisted of less than 15 exons (Figure 1D). Additionally, we determined the number of circRNAs derived from each chromosome (Figure S1A,B). The exonic circRNAs were found to prefer the second exon of the linear transcript as the starting exon; however, the end exon of circRNAs did not show any preference (Figure S1C). 
A

\begin{tabular}{|l|}
\hline \\
\hline Identified circRNAs \\
\hline Normal diet \\
Exonic circRNAs \\
Intronic circRNAs \\
Intergenic circRNAs \\
High-fat diet \\
Exonic circRNAs \\
Intronic circRNAs \\
Intergenic circRNAs
\end{tabular}

|CIRCexplorer2 |

67146

49236

46033

3203

43545

41679

1866
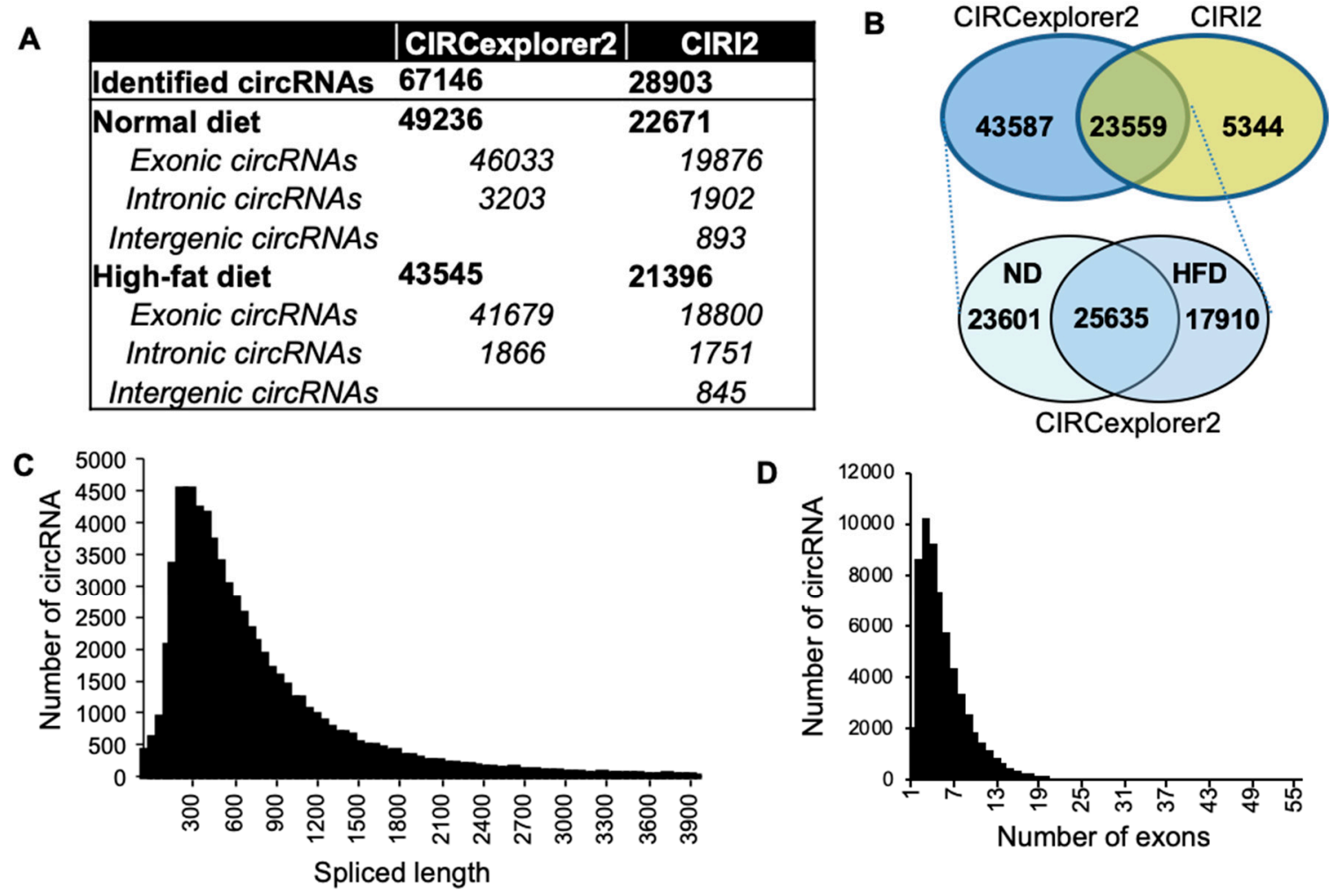

Figure 1. Annotation and characteristics of circular RNAs (circRNAs) in mouse pancreatic islets. (A) Summary of circRNAs identified in pancreatic islets of mice fed with normal diet (ND) and high-fat diet (HFD), using CIRCexplorer2 and CIRI2. (B) Venn diagram showing the overlapped circRNAs detected in pancreatic islets using CIRI2 and CIRCexplorer2 (top). Venn diagram of circRNAs detected by CIRCexplorer2 in pancreatic islets of mice fed with ND or HFD (bottom). (C) Distribution of the spliced length of circRNAs with length up to 4000 nucleotides in pancreatic islets detected by CIRCexplorer2. (D) The exon number distribution for exonic circRNAs detected with CIRCexplorer2.

Since pancreatic islets contain alpha, beta, delta, and PP cells, we used mouse pancreatic $\beta$ TC6 cell line for validation of a selected list of circRNAs from RNA-seq analysis (Figure S2A). Additionally, we analyzed their abundance in $\beta$ TC6 cells using RT-qPCR analysis (Figure S2B). Furthermore, the selected circRNAs were PCR-amplified from mouse pancreatic islets and $\beta$ TC6 cells using specific divergent primers and were assessed on agarose gel followed by Sanger-sequencing to confirm the amplification of backsplice junction sequences (Figure S3A,B). Furthermore, an RNase R treatment assay was employed to check the circularity of the selected circRNAs. Indeed, RNase R treatment degraded the linear RNAs, while the tested circRNAs showed resistance to RNase R digestion (Figure S3C).

\subsection{Identification of Differentially Expressed (DE) CircRNAs}

To explore the molecular regulation of circRNAs in pancreatic islets, we sought to explore expression profiles of circRNAs in the pancreatic islets of mice fed with HFD compared with ND. Differential expression analysis identified 32 upregulated and 45 downregulated circRNAs in HFD islets compared to ND islets (Figure 2A). As shown in Figure 2B, the differentially expressed circRNAs were clustered based on their expression profiles in ND and HFD samples (Table 1). Interestingly, three of the circRNAs generated from mouse Ins2 were downregulated in islets of mice fed with HFD compared to ND, suggesting a possible role for these circRNAs in the development of diabetes. 
A

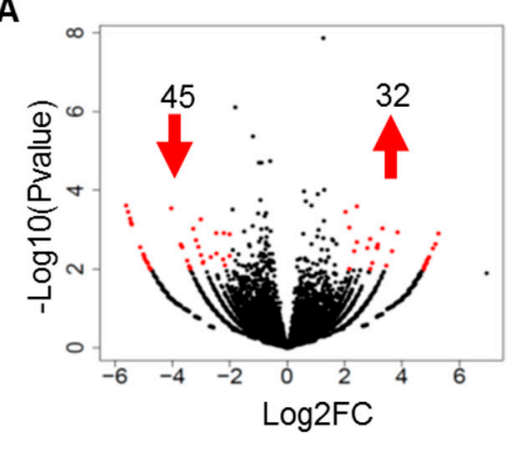

B

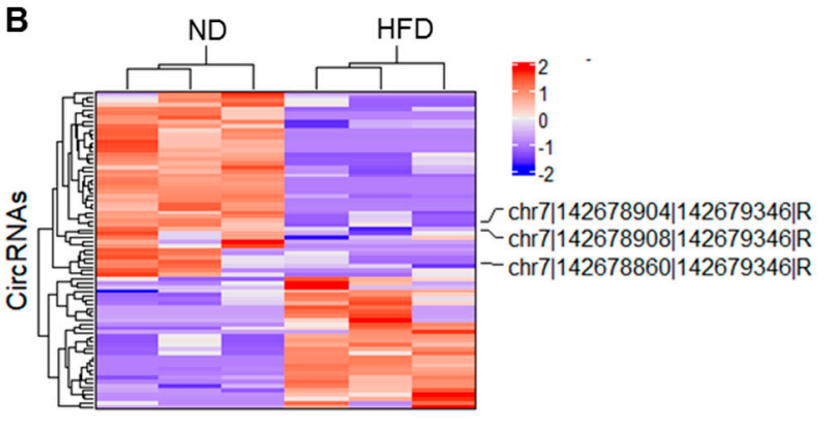

C
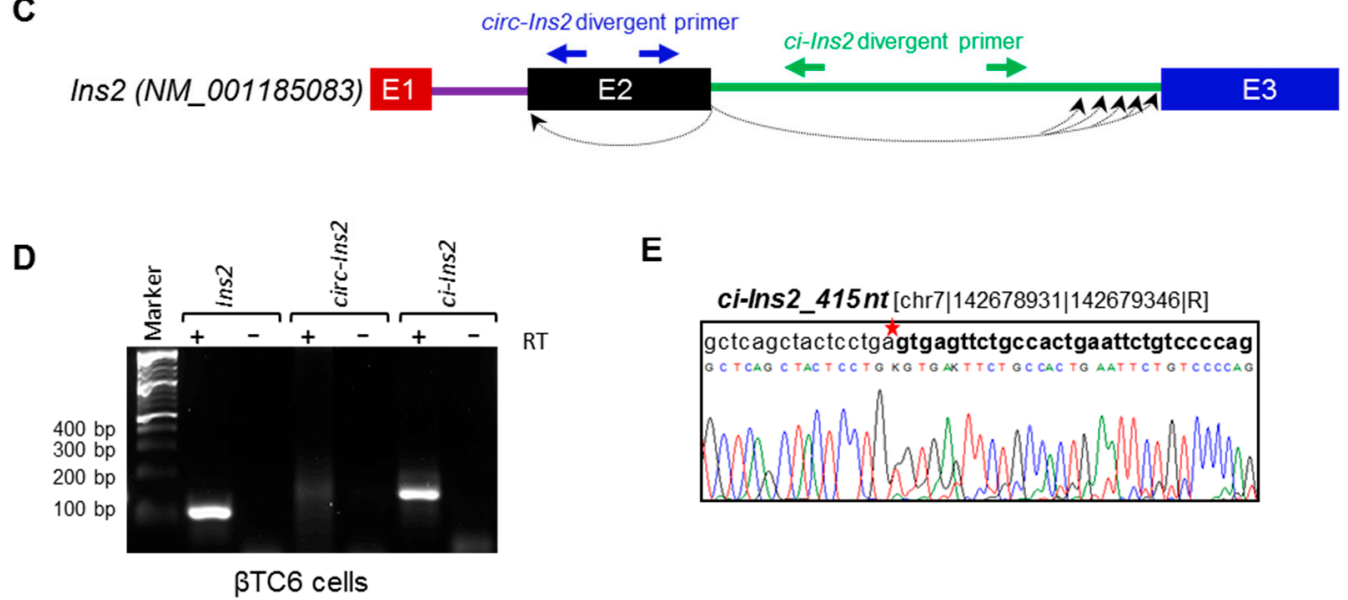

E

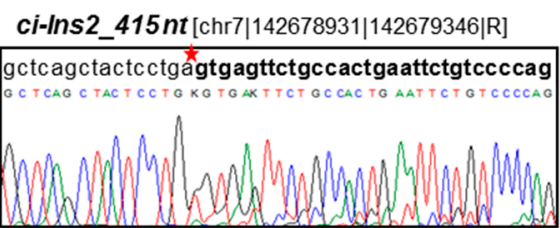

Figure 2. Differential expression and validation of circular RNA derived from the insulin 2 gene. (A) Volcano plot of differentially expressed circRNAs detected by CIRCexplorer2 in pancreatic islets of mice fed with HFD compared to ND. The log2 fold-change greater than 2 and $p$-value less than 0.01 were considered as differentially expressed. The upward and downward arrows indicate upand downregulated circRNAs, respectively. (B) Heatmap representing hierarchical clustering of differentially expressed circRNAs, as mentioned in panel A. Three circRNAs derived from Ins2 are labeled on the heatmap. (C) Schematic representation of mouse Ins2 pre-mRNAs and the location of divergent primers for amplification of $c i r c-I n s 2$, and $c i$-Ins2. The boxes represent the exons, and the lines represent the introns. The dotted curved lines represent the backsplicing or intron lariat junctions. (D) The RT-PCR products of Ins2, circ-Ins2, and ci-Ins2 in $\beta$ TC6 cells resolved and visualized in SYBR Gold-stained 2.5\% agarose gel. (E) PCR products of ci-Ins2 from $\beta$ TC6 cells were purified and Sanger-sequenced to confirm the junction sequences of ci-Ins 2 transcripts.

Table 1. List of differentially expressed circRNAs detected with CIRCexplorer2.

\begin{tabular}{ccccccc}
\hline CircRNA_ID & Name of Isoform & $\begin{array}{c}\text { Name of } \\
\text { Gene }\end{array}$ & $\begin{array}{c}\text { Splice } \\
\text { Length }\end{array}$ & $\begin{array}{c}\text { Type of } \\
\text { CircRNA }\end{array}$ & $\begin{array}{c}\text { logFC } \\
\text { (HFD vs. ND) }\end{array}$ & $\boldsymbol{P}$ Value \\
\hline chr16|20422304|20422485|R & NM_013790 & Abcc5 & 181 & circRNA & -2.9989 & 0.0044 \\
\hline chr1|155601453|155677234|F & NM_028250 & Acbd6 & 310 & circRNA & -3.0915 & 0.0027 \\
\hline chr1|82893582|82894474|F & NM_001347077 & Agfg1 & 892 & ciRNA & -3.6744 & 0.0026 \\
\hline chr1|177102961|177109738|R & NM_011785 & Akt3 & 257 & circRNA & 2.3388 & 0.0035 \\
\hline chr1|177031649|177067333|R & NM_011785 & Akt3 & 658 & circRNA & -4.9995 & 0.0043 \\
\hline chr1|58059034|58065366|F & NM_009676 & Aox1 & 797 & circRNA & -4.7680 & 0.0096 \\
\hline chr13|94493668|94532066|F & NM_009680 & Ap3b1 & 497 & circRNA & 5.1675 & 0.0023 \\
\hline chr9|44751215|44752275|R & NM_145985 & Arcn1 & 314 & circRNA & 3.1211 & 0.0028 \\
\hline chr8|11781154|11785914|F & NM_001113517 & Arhgef7 & 418 & circRNA & 3.3226 & 0.0009 \\
\hline chr12|101932967|101945919|R & NM_029705 & Atxn3 & 638 & circRNA & -3.7032 & 0.0024 \\
\hline chr2|59932104|59960105|R & NM_001001182 & Baz2b & 1064 & circRNA & 2.7952 & 0.0029 \\
\hline chr19|36986454|36992584|F & NM_001080706 & Btaf1 & 1233 & circRNA & 3.8481 & 0.0012 \\
\hline
\end{tabular}


Table 1. Cont.

\begin{tabular}{|c|c|c|c|c|c|c|}
\hline CircRNA_ID & Name of Isoform & $\begin{array}{c}\text { Name of } \\
\text { Gene }\end{array}$ & $\begin{array}{l}\text { Splice } \\
\text { Length }\end{array}$ & $\begin{array}{c}\text { Type of } \\
\text { CircRNA }\end{array}$ & $\begin{array}{c}\log \mathrm{FC} \\
\text { (HFD vs. ND) }\end{array}$ & $P$ Value \\
\hline chr8|124597498|124600487|F & NM_023709 & Capn9 & 339 & circRNA & -4.8492 & 0.0071 \\
\hline chr13|24164800|24178257|R & NM_001311122 & Carmil1 & 233 & circRNA & -3.4788 & 0.0061 \\
\hline chr10|41654941|41656332|R & NM_001358562 & Ccdc162 & 423 & circRNA & 4.7722 & 0.0084 \\
\hline chr6|147507783|147562712|F & NM_001355714 & Ccdc91 & 759 & circRNA & -4.9599 & 0.0054 \\
\hline chr17|42805159|42830105|R & NM_009847 & Cd2ap & 1267 & circRNA & -2.2265 & 0.0056 \\
\hline chr8|105643515|105666792|F & NM_001358924 & Ctcf & 1212 & circRNA & 4.7654 & 0.0098 \\
\hline chr9|3454539|3460131|F & NM_027545 & Cwf1912 & 567 & circRNA & 4.9208 & 0.0052 \\
\hline chr7|55873445|55875088|F & NM_001164661 & Cyfip1 & 362 & circRNA & -5.5388 & 0.0004 \\
\hline chr8|111010720|111011462|R & NM_001190800 & Ddx19b & 416 & circRNA & -3.2670 & 0.0009 \\
\hline chr11|86784878|86793261|R & NM_026191 & Dhx40 & 609 & circRNA & 3.6590 & 0.0035 \\
\hline chr4|99070177|99079849|R & NM_001290636 & Dock7 & 646 & circRNA & -2.9306 & 0.0070 \\
\hline chr14|66824344|66834376|R & NM_009955 & Dpysl2 & 498 & circRNA & -2.4682 & 0.0012 \\
\hline chr15|12878657|12890547|F & NM_001130149 & Drosha & 811 & circRNA & -3.3908 & 0.0091 \\
\hline chr4|59690143|59691338|F & NM_153158 & E130308A19Rik & 1195 & circRNA & 2.9678 & 0.0070 \\
\hline chr4|58872588|58885498|R & NM_001355696 & Ecpas & 689 & circRNA & 4.7628 & 0.0099 \\
\hline chr18|33874141|33891476|R & NM_013512 & Epb4114a & 591 & circRNA & -2.0009 & 0.0013 \\
\hline chr11|26407547|26434500|F & NM_001277273 & Fancl & 267 & circRNA & -4.7565 & 0.0099 \\
\hline chr9|78098345|78104354|R & NM_023605 & Fbxo9 & 401 & circRNA & 4.8614 & 0.0061 \\
\hline chr6|99162838|99435345|R & NM_001347345 & Foxp1 & 491 & circRNA & -3.1755 & 0.0018 \\
\hline chr5|71623854|71642326|R & NM_001359041 & Gabra4 & 929 & circRNA & 2.4293 & 0.0003 \\
\hline chr7|19164639|19164967|R & NM_001080815 & Gipr & 328 & ciRNA & -4.9741 & 0.0046 \\
\hline chr6|86717385|86722665|R & NM_011818 & Gmcl1 & 374 & circRNA & -4.9008 & 0.0063 \\
\hline 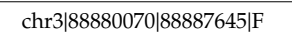 & NM_001242372 & Gon41 & 390 & circRNA & 4.9467 & 0.0049 \\
\hline chr3|20058898|20076584|F & NM_001355097 & Hltf & 1131 & circRNA & -4.8942 & 0.0064 \\
\hline chr16|4762558|4763846|F & NM_001136066 & Hmox2 & 237 & circRNA & 3.1462 & 0.0029 \\
\hline chr6|51465178|51466222|R & NM_016806 & Hnrnpa2b1 & 144 & circRNA & -5.4402 & 0.0006 \\
\hline chr7|142678908|142679346|R & NM_001185083 & Ins2 & 438 & ciRNA & -2.6556 & 0.0050 \\
\hline chr7|142678860|142679346|R & NM_001185083 & Ins2 & 486 & ciRNA & -3.3804 & 0.0094 \\
\hline chr7|142678904|142679346|R & NM_001185083 & Ins2 & 442 & ciRNA & -3.3891 & 0.0090 \\
\hline chr13|44731712|44848421|F & NM_001205044 & Jarid2 & 482 & circRNA & 5.2731 & 0.0012 \\
\hline chr4|149251740|149253751|R & NM_001290995 & Kif1b & 156 & circRNA & -5.1133 & 0.0028 \\
\hline chr12|111785271|111785502|F & NM_001361611 & Klc1 & 118 & circRNA & -3.6522 & 0.0028 \\
\hline chr1|134475787|134485913|F & NM_001311136 & Klhl12 & 418 & circRNA & 2.1707 & 0.0099 \\
\hline chr18|56739820|56743315|F & NM_010721 & Lmnb1 & 552 & circRNA & 5.0791 & 0.0030 \\
\hline chr7|72161139|72185865|R & NM_001024703 & Mctp2 & 503 & circRNA & -5.0067 & 0.0042 \\
\hline chr4|87840681|87880148|R & NM_027326 & Mllt3 & 935 & circRNA & 2.8933 & 0.0017 \\
\hline chr11|62419597|62423067|R & NM_001252313 & Ncor1 & 376 & circRNA & -2.0002 & 0.0045 \\
\hline chr8|61086398|61089799|F & NM_001293637 & Nek1 & 418 & circRNA & -2.9191 & 0.0065 \\
\hline chr5|24692806|24695590|F & NM_001305264 & Nub1 & 301 & circRNA & -4.7608 & 0.0098 \\
\hline chr2|121429453|121434093|F & NM_007952 & Pdia3 & 665 & circRNA & 4.8197 & 0.0076 \\
\hline chr5|65663855|65666311|R & NM_001081321 & Pds5a & 389 & circRNA & 4.7741 & 0.0096 \\
\hline chr8|109876802|109895641|F & NM_001122594 & Phlpp2 & 415 & circRNA & -4.8009 & 0.0090 \\
\hline chr6|65862914|65901859|F & NM_027547 & Prdm5 & 758 & circRNA & -3.0054 & 0.0005 \\
\hline chr6|112665277|112681676|R & NM_001167730 & Rad18 & 761 & circRNA & 2.0348 & 0.0004 \\
\hline chr17|65857661|65864732|R & NM_001198949 & Ralbp1 & 1103 & circRNA & 3.1595 & 0.0024 \\
\hline chr4|135418379|135420419|R & NM_022980 & Rcan3 & 346 & circRNA & -2.1644 & 0.0079 \\
\hline chr5|63924734|63938033|R & NM_145923 & Rell1 & 734 & circRNA & 2.1681 & 0.0009 \\
\hline chr17|29634660|29636022|F & NM_021419 & Rnf8 & 313 & circRNA & 3.4555 & 0.0082 \\
\hline chr7|97616842|97653207|F & NM_001081267 & Rsf1 & 546 & circRNA & -5.4669 & 0.0005 \\
\hline chr3|130040673|130041447|R & NM_207209 & Sec24b & 774 & circRNA & 2.8977 & 0.0098 \\
\hline chr6|4707073|4719496|R & NM_001130188 & Sgce & 553 & circRNA & -2.4581 & 0.0040 \\
\hline chr11|52236836|52243758|F & NM_011543 & Skp1a & 315 & circRNA & -3.4104 & 0.0085 \\
\hline chr6|142101591|142133232|R & NM_023718 & Slco1a6 & 936 & circRNA & 4.8197 & 0.0076 \\
\hline
\end{tabular}


Table 1. Cont.

\begin{tabular}{ccccccc}
\hline CircRNA_ID & Name of Isoform & $\begin{array}{c}\text { Name of } \\
\text { Gene }\end{array}$ & $\begin{array}{c}\text { Splice } \\
\text { Length }\end{array}$ & $\begin{array}{c}\text { Type of } \\
\text { CircRNA }\end{array}$ & $\begin{array}{c}\text { logFC } \\
\text { (HFD vs. ND) }\end{array}$ & $P$ Value \\
\hline chr17|71455604|71465669|R & NM_028887 & Smchd1 & 452 & circRNA & -5.4092 & 0.0007 \\
\hline chr1|192930477|192986882|R & NM_001301370 & Syt14 & 1103 & circRNA & 2.4311 & 0.0021 \\
\hline chr10|56087530|56089839|R & NM_001033385 & Tbc1d32 & 326 & circRNA & -4.8798 & 0.0066 \\
\hline chr11|121602987|121611748|F & NM_029878 & Tbcd & 871 & circRNA & -5.4350 & 0.0007 \\
\hline chr1|135304429|135309198|R & NM_001360857 & Timm17a & 304 & circRNA & -2.2046 & 0.0012 \\
\hline chr1|37783816|37811027|R & NM_207228 & Tsga10 & 732 & circRNA & 4.9306 & 0.0051 \\
\hline chr5|92166530|92167333|F & NM_019490 & Uso1 & 260 & circRNA & 4.8256 & 0.0075 \\
\hline chr11|85077264|85083894|R & NM_001029934 & Usp32 & 385 & circRNA & -3.3658 & 0.0095 \\
\hline chr11|23333438|23345217|F & NM_001190401 & Usp34 & 690 & circRNA & 4.8640 & 0.0069 \\
\hline chr7|99065799|99099473|R & NM_178635 & Uvrag & 320 & circRNA & -5.6041 & 0.0002 \\
\hline chr3|108618489|108638757|F & NM_001358053 & Wdr47 & 2071 & circRNA & -4.0332 & 0.0003 \\
\hline chr8|107483331|107485642|F & NM_025830 & Wwp2 & 235 & circRNA & -3.4087 & 0.0083 \\
\hline
\end{tabular}

\subsection{Multiple Exonic and Intronic CircRNAs are Generated from Ins2 Genes}

Previous research has shown that alternative splicing and backsplicing events can generate multiple exonic and intronic circRNAs from a single gene [12,34]. Furthermore, circRNA biogenesis is involved in alternative splicing of the host gene, which could lead to altered gene expression [24]. Here, our RNA-seq data analysis using CIRCexplorer2 detected multiple exonic and circular intronic lariat RNAs (ciRNA) derived from insulin genes in mice (Table S4). Surprisingly, the RNA-seq data identified 39 circRNAs generated from the mouse Ins 2 gene, out of which only two are generated from exon 2 while the rest is generated from intron2 of Ins2 pre-mRNA. RT-PCR amplification of the circular exonic and intronic RNAs, with specific divergent primers in $\beta$ TC6 cells, confirmed the expression of circ-Ins2 and ci-Ins2 transcripts (Figure 2C,D). PCR with RT and no-RT controls indicated that circ-Ins2 and ci-Ins2 are circular transcripts generated from Ins2 pre-mRNA. However, the expression of circ-Ins2 was very low and barely amplified in $\beta$ TC 6 cells and mice pancreatic islets (Figure S4). Furthermore, Sanger sequencing of the circ-Ins2 PCR products could not consistently confirm any specific circular transcript from exon2 of Ins2 (data not shown).

Although our RNA-seq data analysis detected 37 ci-Ins2 RNAs, RT-PCR using divergent primer targeting the intron2 of Ins2 gene amplified a single major product (Figure 2D). Sanger sequencing of the PCR products detected the ci-Ins2 [chr7|142678931|142679346|R] with a length of $415 \mathrm{nt}$ (Figure 2E). Since the RNA-seq predicted many ci-Ins 2 transcripts, the PCR products were cloned and sequenced to verify the $c i$-Ins2 lariat junction sequence. Consistent with a previous publication, the lariat branch point showed a mismatch due to error incorporated during reverse transcription at the $2^{\prime}-5^{\prime}$ lariat junction (Figure S5) [35]. Intronic lariat derived ci-RNAs are known to be very stable due to their resistance to debranching (DBR) enzymes as well as other exonuclease activity [16,36]. Here, we checked the circularity of $c i$-Ins 2 by digesting the total RNA from $\beta$ TC 6 cells and mouse pancreatic islets with RNase R exonuclease. Indeed, RNase R treatment degraded linear Ins1 and Ins 2 mRNAs, not the ci-Ins 2 in both $\beta$ TC 6 cells and pancreatic islets (Figure 3A,B). These analyses suggest that ci-Ins2 transcripts are bona fide stable circular transcripts.

\subsection{Alternate Branchpoint Selection Generates Multiple Ci-Ins2 Lariats}

Multiple ci-Ins2 transcripts were generated from Ins2 pre-mRNA, and three of them were differentially expressed in HFD (Table 1 and Table S4). Since divergent primers used against $c$-Ins2 could amplify multiple circular transcripts, we tried to perform RT-PCR analysis for the ci-Ins2_415 [415 nt; chr7|142678931|142679346|R], ci-Ins2_438 (438 nt; chr7|142678908|142679346|R], ci-Ins2_442 [442 nt; chr7|142678904|142679346|R], and ci-Ins2_486 [486 nt; chr7|142678860|142679346|R], using the primer spanning the backsplice junction sequence. As shown in Figure 4A, the forward primer spans the junction targeting specific ci-Ins2 transcripts, while the reverse primer was common for all four transcripts tested here. RT-PCR analysis of these ci-Ins2 transcripts using RT, no-RT, and 
RNase-R-treated samples from $\beta$ TC6 cells suggested the expression of multiple ci-Ins2 transcripts in beta cells (Figure 4B). Interestingly, all the ci-Ins2 variants start at $5^{\prime}$ splice site of intron 2 of Ins 2 pre-mRNA, while the end is variable (Figure S6). These variants may be generated due to alternative branchpoint selection during Ins2 pre-mRNA splicing, consistent with previous findings [37].

A

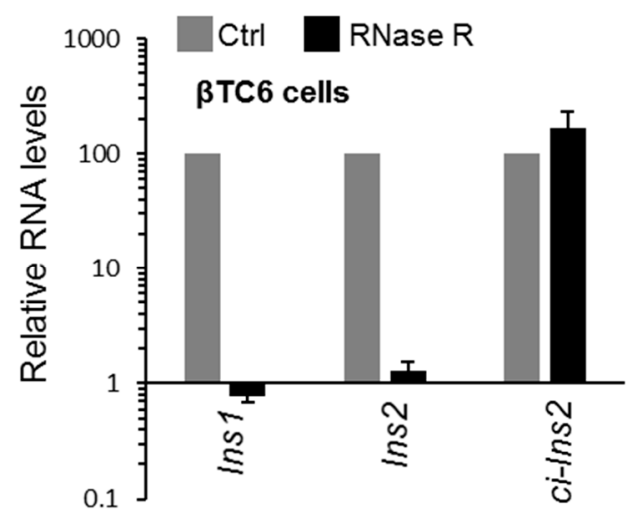

B

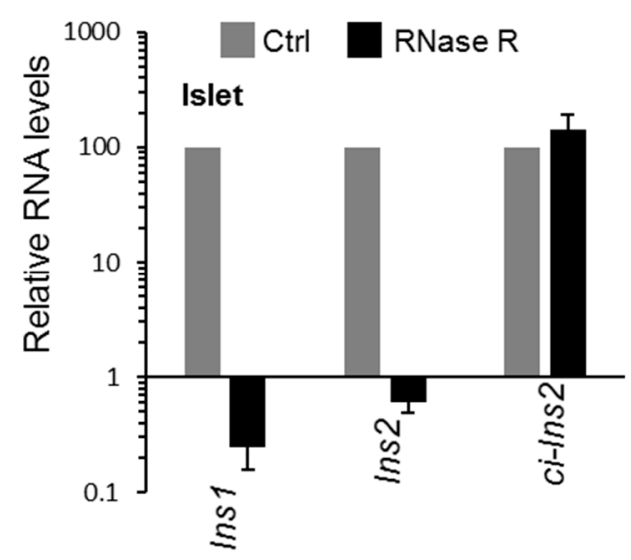

Figure 3. Circular nature and stability of $c i-I n s 2$. (A,B) RT-qPCR analysis showing the levels of mRNAs and ci-Ins2 upon RNase R treatment in $\beta$ TC6 cells (A) and pancreatic islets (B). Data represent the means \pm SEM from three independent experiments.

A

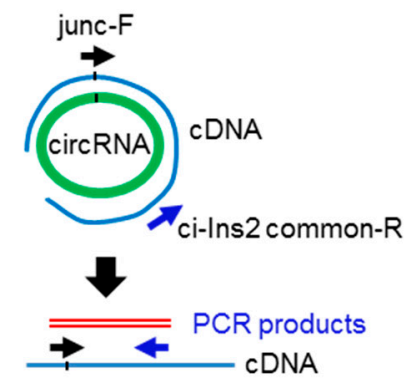

B

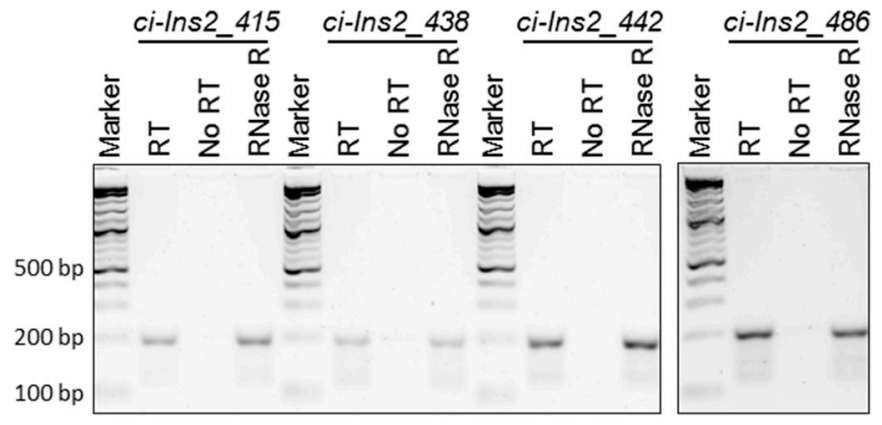

Figure 4. Multiple ci-Ins2 transcripts are expressed in $\beta$ TC6 cells. (A) Schematic representation of RT-PCR verification of circular RNAs, with the forward primer spanning the backsplice junction. Green circle represents the circRNA template, the blue line represents cDNA, arrows represent the PCR primers, and the red line represents expected PCR products. (B) PCR products of individual circular RNAs in $\beta$ TC6 cells total RNA cDNA (RT), no-RT, and RNase-R-treated samples were resolved on $2.5 \%$ agarose gel stained with SYBR-Gold.

\subsection{Exposure of $\beta$ TC6 Cells to Palmitate and High Glucose Alters the Level of Ci-Ins2}

The RNA-seq data suggested a decrease in ci-Ins2 level in pancreatic islets from mice fed with HFD. Since long-term exposure to elevated glucose and/or fatty acids in the blood are known to impair pancreatic $\beta$-cell physiology during the development of diabetes, we wanted to investigate the impact of elevated levels of fatty acids and glucose on the expression of ci-Ins2 in the $\beta$ TC 6 cells. Consistent with previous reports, palmitate treatment in the presence of high glucose reduced the expression of Ins1 and Ins2 mRNAs (Figure 5A) [38-41]. Furthermore, ci-Ins2 expression was significantly reduced in palmitate-treated cells compared with the control-treated cells (Figure 5A). However, we did not evaluate the effect of palmitate on beta-cell apoptosis. Additionally, to study the effect of long-term exposure to high glucose on ci-Ins2 levels, RT-qPCR analysis was performed in $\beta$ TC6 cells cultured in low or high glucose conditions for 7 days. As shown in Figure 5B, ci-Ins2 and the host gene Ins 2 mRNA were significantly upregulated in $\beta$ TC 6 cells cultured in the high glucose condition. However, further experiments are underway to find the regulatory effect of ci-Ins2 on Ins2 mRNA or vice versa. 
A

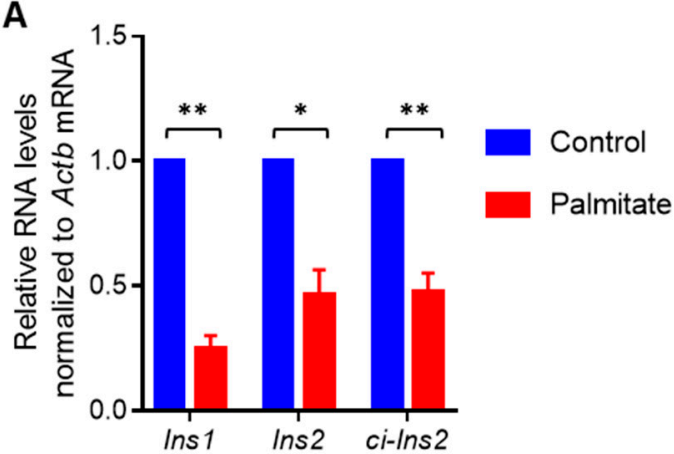

B

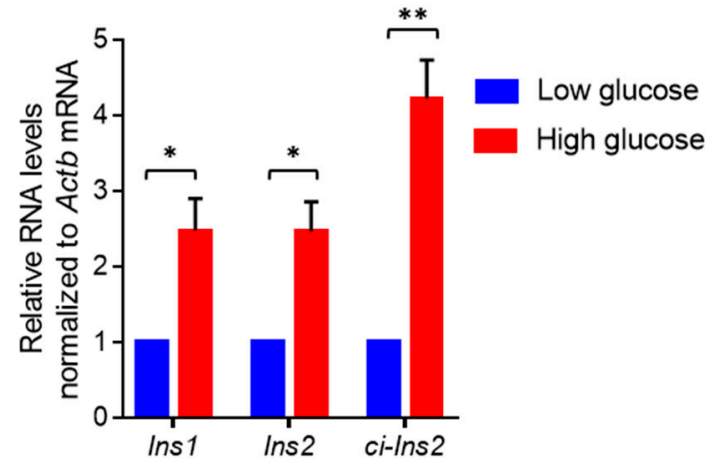

Figure 5. Altered expression of ci-Ins2 in $\beta$ TC6 cells exposed to palmitate or high glucose. (A) RT-qPCR analysis of Ins1, Ins2 and ci-Ins2 in $\beta$ TC6 cells cultured for 3 days in DMEM ( $25 \mathrm{mM}$ glucose $)+1 \%$ fetal bovine serum (FBS) with or without $0.5 \mathrm{mM}$ sodium palmitate. (B) RT-qPCR analysis of Ins1, Ins2 and ci-Ins2 in $\beta$ TC 6 cells cultured for 7 days in low glucose $(2.5 \mathrm{mM})$ or high glucose $(25 \mathrm{mM})$ containing DMEM supplemented with $15 \%$ FBS. All results represent means \pm SEM from 4 independent experiments. ${ }^{*} p<0.05,{ }^{* *} p<0.001$.

\subsection{Splicing Factors are Predicted to Interact with the Ins2 pre-mRNA and ci-Ins2}

It has been established that several RBPs modulate circRNA biogenesis, and circRNAs regulate the function of RBPs by acting as a decoy [10]. Prediction of RBPs interacting with pre-mRNA of Ins2 using beRBP software has identified many splicing regulators, including SRSF3, PTBP1, CUG-BP, and MBNL1 (Figure 6, Table S5) [42]. The majority of the predicted proteins are not known to regulate Ins2 mRNA splicing. However, their role in the ci-Ins2 biogenesis warrants further investigation. Additionally, several RBPs, including SRSF3, PTBP1, CUG-BP, MBNL1, and TARDBP, were predicted to associate with $c i$-Ins2, suggesting that $c i$-Ins 2 might act as a sponge for these RBPs. Interestingly, PTBP1 and TARDBP (TDP-43) are known to be involved in insulin expression and secretion in pancreatic beta-cells $[43,44]$. However, dedicated efforts are underway to delineate the role of $c i$-Ins 2 in $\beta$-cells by acting as a decoy for any of these RBPs.

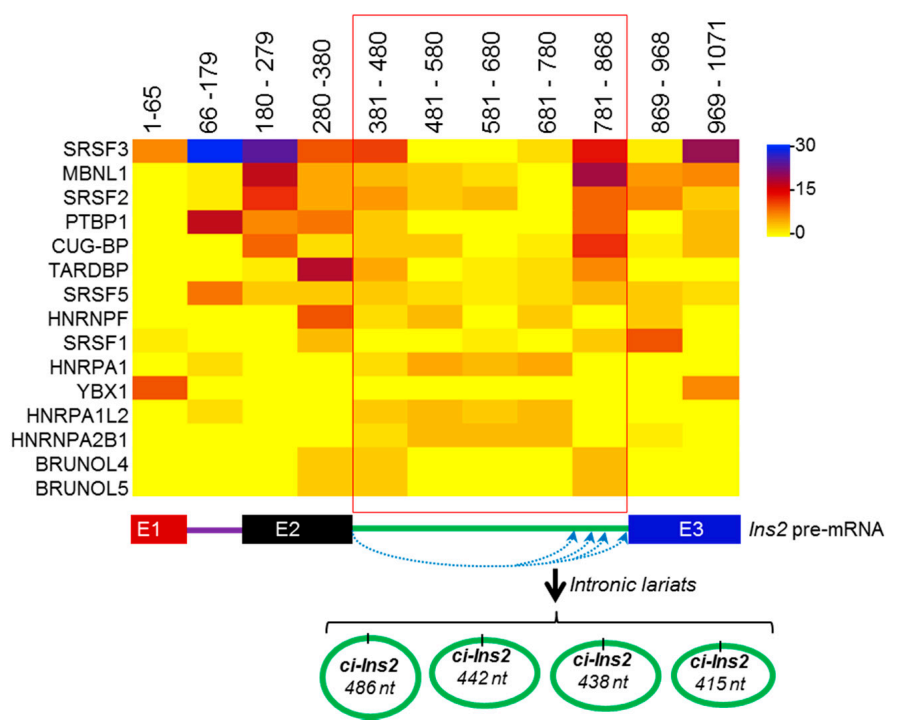

Figure 6. RNA-binding proteins (RBPs) predicted to associate with ci-Ins2 and Ins2 pre-mRNA. Heatmap of RBPs predicted by the beRBP algorithm to have ten or more number of binding sites on mouse Ins2 pre-mRNA (top). The scale bar colors represent the number of binding sites on the specific region of Ins2 pre-mRNA. Schematic representation of biogenesis of multiple ciRNAs from Ins 2 pre-mRNA (bottom). Straight lines and boxes represent introns and exons, respectively. The blue dotted arrows represent alternate intron lariat formation, generating multiple ci-Ins 2 transcripts. 


\subsection{The ci-Ins2 May Regulate Beta-Cell Physiology by Sponging miRNAs}

To investigate how ci-Ins2 modulates $\beta$-cell physiology, we sought to identify ci-Ins2 (486 nt) associated miRNAs. Interestingly, a number of miRNAs were predicted to interact with ci-Ins2 using miRDB (Figure 7A) [45]. The majority of the miRNAs were found to be common for all four validated ci-Ins2 transcripts. Furthermore, we identified downstream mRNAs targeted by the miRNAs associated with ci-Ins2 using various software, including miRDB, RNA22, miRTarBase, and TargetScan [45-48]. The mRNAs predicted by two or more software and are differentially expressed in islets of mice fed with HFD compared to ND were further analyzed for GO and pathway enrichment (Table S6) [49]. GO-slim biological process analysis suggested that the target mRNAs were mainly enriched in chemical synaptic transmission, trans-synaptic signaling, response to endogenous stimulus, synaptic signaling, and regulation of localization and cellular localization. (Figure 7B). GO-slim cellular component analysis suggested the enrichment of various terms, including plasma membrane, cell periphery, membrane protein complex, cell part, cell, and membrane. Additionally, GO-slim molecular function analysis identified genes involved in anion binding, ion binding, carbohydrate derivative binding, enzyme binding, and small GTPase binding. (Figure 7B). Furthermore, pathway analysis of the target mRNAs using PANTHER identified several enriched pathways, including Axon guidance mediated by Slit/Robo, p53 pathway, 5HT4 type receptor mediated signaling pathway, integrin signaling pathway, opioid proopiomelanocortin pathway, GABA-B receptor II signaling, insulin/IGF pathway-protein kinase B signaling cascade, and PDGF signaling pathway. (Figure 7C) [49]. In sum, these data indicate that the circRNA-miRNA-mRNA axis may help us to explore the molecular mechanism of ci-Ins2 in $\beta$-cell physiology.

A

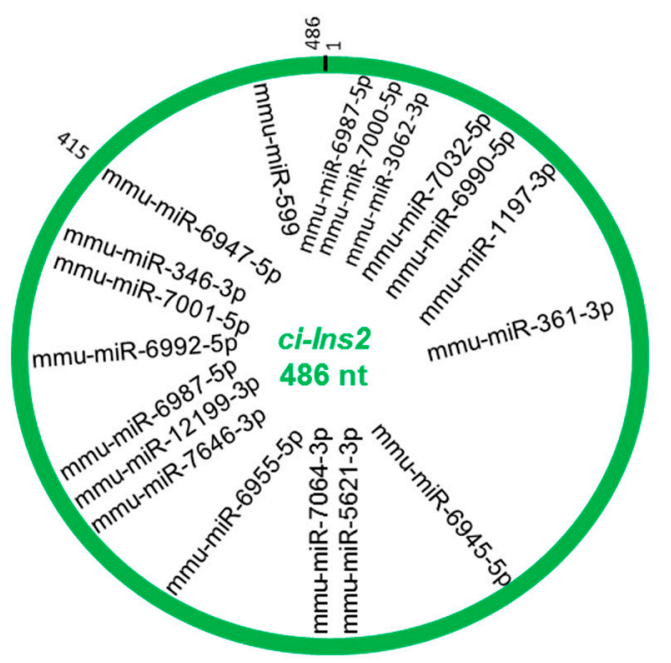

B

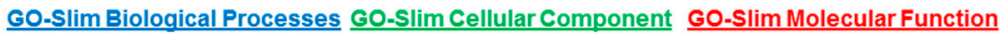

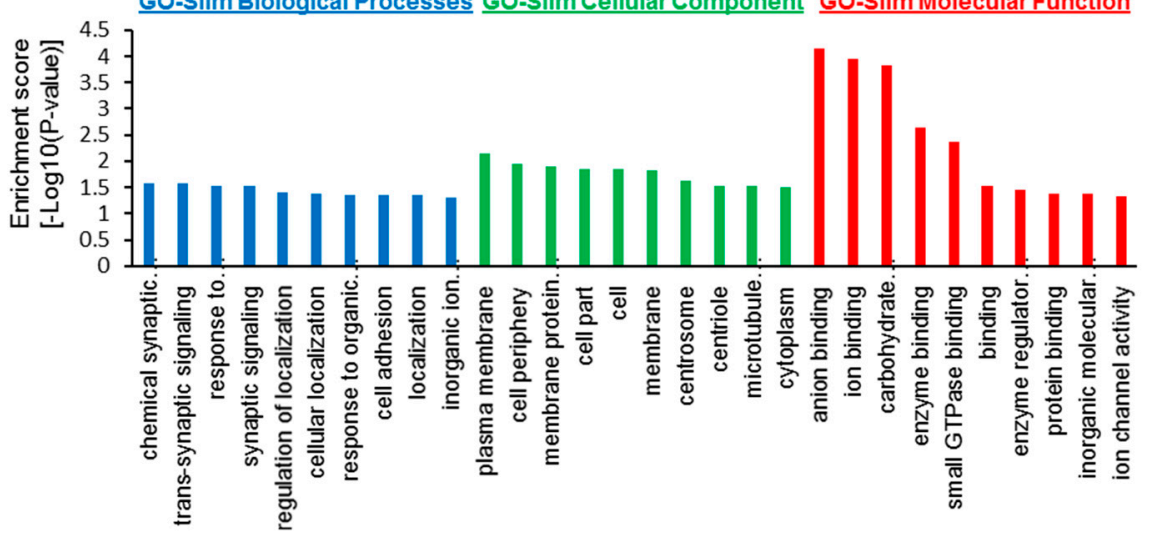

Figure 7. Cont. 


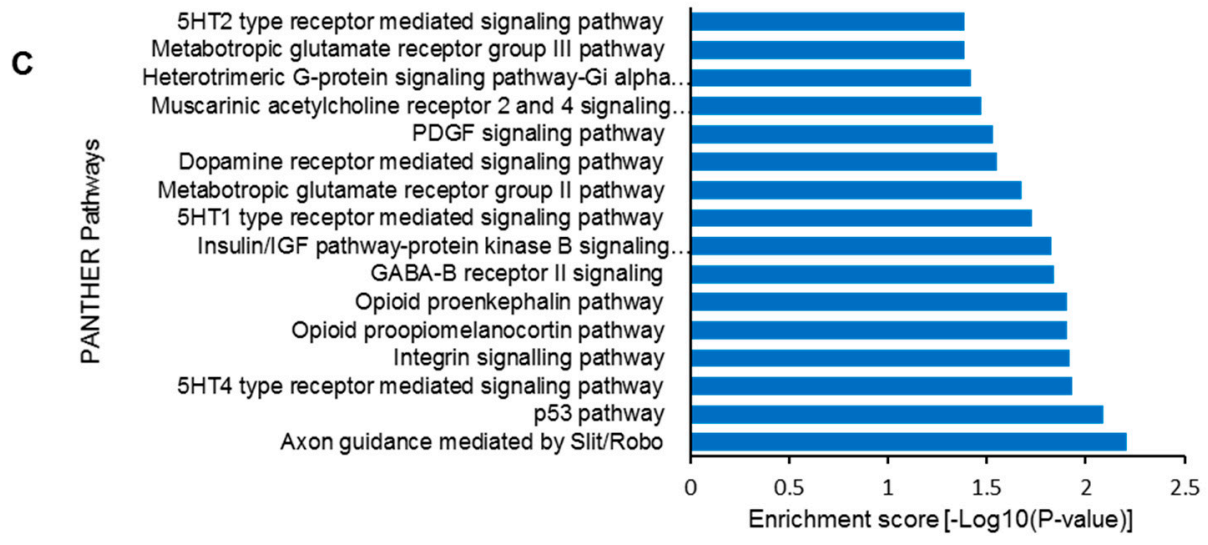

Figure 7. Prediction of $c i$-Ins2-miRNA-mRNA regulatory axis. (A) miRNAs predicted by miRDB to associate with ci-Ins2 (486 nt). (B) The top $10 \mathrm{GO}$ terms with the highest number of enriched genes for biological processes, cellular components, and molecular function for the mRNA targets of miRNAs associated with ci-Ins2 (486 nt). (C) PANTHER pathways enriched for the mRNA targets of miRNAs associated with ci-Ins2 (486 nt).

\section{Discussion}

Recent developments in RNA-sequencing technologies have helped in exploring the characteristics of circRNAs across various tissues in various organisms [11]. The circRNAs have been shown to have tissue- and cell-line-specific expression. CircRNAs have been implicated in different pathophysiological conditions and regulate gene expression by acting as a sponge for RBPs and microRNAs, and competing with linear splicing [10]. However, the molecular mechanism of circRNA expression and their role in pancreatic $\beta$-cells is not understood completely [28].

Dysregulation of insulin production from pancreatic $\beta$-cells is one of the key causes of the development of diabetes $[50,51]$. Here, we explored the expression profile and the regulatory functions of circRNAs in $\beta$-cells. Recent studies have identified a large number of circRNAs in human and mouse pancreatic islets [32]. In this study, we used publicly available RNA-sequencing data to identify differentially expressed circRNAs in a diet-induced obesity mouse model. In this study, we detected $>70,000$ circRNAs in mouse islets, and several circRNAs were found to be dysregulated in the islets of mice fed with HFD compared to ND. Interestingly, three of the differentially expressed circRNAs were found to be generated from the mouse Ins2 gene. In the mouse pancreatic islets, most genes generate one or a few circRNAs, supporting the notion that specific exons/introns are circularized in a regulated manner. By contrast, RNA-seq data indicated that Ins 2 pre-mRNA undergoes alternative backsplicing and generates multiple circRNAs. This data was further validated by RT-PCR with divergent primers placed on exon2 and intron2 of Ins2 pre-mRNA, where multiple alternative circular transcripts were amplified (Figure 2). RT-PCR amplification of circ-Ins2 resulted in a smear without a specific PCR product, and the level of expression was found to be very low in islets and $\beta$ TC6 cells. Furthermore, RNA-seq data suggested the expression of 37 intronic ci-Ins 2 transcripts from intron 2 of Ins 2 pre-mRNA. However, PCR amplification of intron 2 of Ins2 pre-mRNA using the divergent primers resulted in the amplification of a product corresponding to ci-Ins 2 with a length of $415 \mathrm{nt}$. Furthermore, RT-PCR analysis using the primer spanning the circRNA junction confirmed the expression of multiple circular intronic RNAs from intron2 that are collectively termed as ci-Ins 2 , with the longest one with $486 \mathrm{nt}$ (Figure 4). In principle, the ci-Ins2 RNAs are intron lariats generated by $2^{\prime}-5^{\prime}$ end ligation during splicing $[16,35]$. However, we cannot exclude the possibility of some ci-Ins2 RNAs with $3^{\prime}-5^{\prime}$ end ligation. This observation supports the recent study that reported the use of multiple branchpoints during splicing in humans [37]. The usage of multiple branchpoints in Ins2 pre-mRNA splicing may be advantageous to mutations and genetic variations and may be differentially regulated by specific splicing regulators. Although RNA-seq identified many intron-derived ci-Ins2 RNAs, our 
PCR sequencing could validate the expression of only a few of them in $\beta$ TC6 cells. The number of ci-Ins2 RNAs identified in our PCR is far from complete as low abundant transcripts were most likely missed, and many of the lariat junctions differed by a few nucleotides, which is difficult to distinguish with primers spanning the junction sequence.

CircRNAs are resistant to exonuclease mediated degradation due to the lack of free ends [19,20,36,52]. As expected, ci-Ins2 transcripts were found to be resistant to RNase R treatment. Furthermore, the junction sequences of $c i$-Ins2 transcripts are similar to the previously published ci-RNA consensus sequence, suggesting that some of the ci-Ins2 transcripts might be resistant to debranching (DBR) enzymes [16]. Since there are several transcripts of ci-Ins2 generated due to alternate branchpoint selection and the huge amount of Ins2 pre-mRNA transcription in $\beta$-cells, some of these lariats may be rapidly degraded by DBR enzymes. We hypothesize that ci-Ins2 transcripts having a lariat junction sequence similar to the ci-RNA consensus sequence are resistant to DBR activity and remain stable (Figure S6B). However, further investigation is required to distinguish the stable ci-Ins2 lariat population that is resistant to DBR, as well as to find whether the $c i$-Ins2 transcripts contain $2^{\prime}-5^{\prime}$ or $3^{\prime}-5^{\prime}$ junctions.

It has been well established that long-term exposure of pancreatic $\beta$-cells to elevated levels of fatty acids and high glucose leads to impaired insulin transcription and secretion from pancreatic $\beta$-cells. Since we could not validate the altered expression of ci-Ins2 in the HFD-fed animal models, we used the in vitro diabetic model, where the $\beta$ TC 6 were cultured in the presence of high concentration of palmitate and/or glucose [38-40]. Palmitate in the presence of high glucose is known to inhibit insulin transcription and secretion from $\beta$-cells [38-40]. As expected, our data suggested that palmitate in the presence of high glucose inhibited insulin gene expression and decreased ci-Ins2 levels (Figure 5A). Additionally, glucose has been known to enhance insulin gene transcription and splicing [5,7]. Our data suggested that the levels of $c i$-Ins2, along with Ins2 mRNA, were significantly upregulated in high-glucose treated cells compared to cells cultured in low glucose (Figure 5B). These data suggest that the altered expression of $c i-I n s 2$ could be associated with the levels of Ins2 pre-mRNA transcription. Since ciRNAs are known to positively regulate transcription of their parent gene, the possibility of Ins2 gene transcription regulation by ci-Ins2 cannot be ruled out. However, further experiments are required to find the role of ci-Ins2 on Ins2 expression.

Previous work has indicated that inverted Alu sequences and RBPs regulate circRNA biogenesis $[15,19,53]$. To study the possible involvement of RBPs and splicing factors in the biogenesis of $c i$-Ins2, we analyzed the RBP binding sites in the Ins2 pre-mRNA using the beRBP algorithm (Figure 6). This computational analysis identified several binding motifs for SRSF3, PTBP1, MBNL1, CUG-BP, SRSF5, and TARDBP on Ins2 pre-mRNA, including intron2 that generates ci-Ins2 (Figure 6). RBPs such as PTBP1 and TARDBP (TDP-43) have been shown to regulate insulin mRNA stability and early-stage insulin secretion, respectively $[43,44]$. We believe that altered expression of ci-Ins 2 possibly affects insulin expression and secretion from pancreatic $\beta$-cells by sponging PTBP1 and TARDBP. However, additional experiments are required to study the interaction of any of these RBPs with ci-Ins2 and their role in insulin biosynthesis or secretion. Additionally, whether any of these RBPs are implicated in the alternative circularization of Ins 2 producing multiple ci-Ins 2 transcripts warrants further investigation. Since circRNAs are very well known to regulate gene expression by acting as miRNA sponges, we also analyzed the miRNAs associated with ci-Ins2. Our results suggest that ci-Ins2 transcripts contain potential miRNA binding sites, indicating their potential to act as a decoy for the target miRNAs. Prediction of a circRNA-miRNA-mRNA regulatory network for $c i$-Ins2 identified several genes that are involved in key biological processes and pathways known to regulate $\beta$-cell physiology (Figure 7). Additionally, the circRNA-miRNA-mRNA regulatory axis discovered here will provide a better understanding of the complex regulatory relationship and mechanism of the development of diabetes. Since these analyses were based on computational predictions, further experimental evidence is required to validate the target miRNA/mRNA expression and discover the underlying molecular mechanisms regulating $\beta$-cell physiology. 


\section{Materials and Methods}

\subsection{CircRNA Annotation}

Circular RNAs were identified in publicly available RNA-sequencing data from pancreatic islets of mice fed with ND and HFD (accession GSE92602/PRJNA358100) [33]. Briefly, the raw RNA-seq reads were downloaded from SRA, and the quality was checked with FastQC. The reads were aligned to the mouse genome ( $\mathrm{mm} 10)$ using STAR aligner, and the alignment information was parsed using the CIRCexplorer2 parse module followed by identification and quantification of circRNAs using the CIRCexplorer2 annotation module [14]. Additionally, the Burrows-Wheeler aligner was used to align the reads with the mouse genome (mm10) followed by circRNA identification with CIRI2 (v 2.6) [54]. The differential expression of circRNAs was analyzed using the edgeR package [55].

\subsection{Animals and Pancreatic Islet Isolation}

Male C57Bl/6 mice with the age of 2-5 months were acquired from the Institute of Life Sciences breeding colonies. Pancreatic islets were isolated from the mice pancreas by collagenase digestion, followed by the Ficoll gradient separation method [56]. Briefly, the whole pancreas was dissected into small pieces in Hanks' balanced salt solution (HBSS) and digested for $20 \mathrm{~min}$ at $37^{\circ} \mathrm{C}$ with HBSS containing $0.5 \mathrm{mg} / \mathrm{mL}$ collagenase. The digested pancreas was washed with HBSS and layered on Ficoll (Sigma Aldrich) gradient, followed by centrifugation to isolate pancreatic islets. The isolated islets were washed with HBSS and were cultured in RPMI medium (Thermo Fisher Scientific) supplemented with $20 \%$ fetal bovine serum (FBS, Gibco) and antibiotics. All animal procedures were performed in agreement with the institutional animal ethics committee of the Institute of Life Sciences.

\section{3. $\beta$ TC6 Cell Culture and In Vitro Treatments}

Mouse $\beta$ TC6 cells were cultured in DMEM containing 15\% FBS and antibiotics and were maintained in a $5 \% \mathrm{CO}_{2}$ humidified atmosphere at $37^{\circ} \mathrm{C}$ [56]. For glucose treatment experiments, $\beta \mathrm{TC} 6$ cells were cultured for 7 days in low glucose (2.5 mM) DMEM or high glucose (25 mM) DMEM supplemented with $15 \%$ FBS and antibiotics. Palmitate $(100 \mathrm{mM})$ was prepared in $50 \%$ ethanol and FFA-free BSA $(2 \mathrm{mM})$ was prepared in DMEM [40]. The palmitate solution was diluted 10 times with the BSA and incubated for $1 \mathrm{~h}$ at $37^{\circ} \mathrm{C}$ to obtain the BSA-conjugated palmitate stock solution with $10 \mathrm{mM}$ palmitate. For palmitate treatment, $\beta$ TC6 cells cultured in high glucose $(25 \mathrm{mM})$ DMEM supplemented with $1 \%$ FBS were treated with BSA-conjugated palmitate at a final concentration of $0.5 \mathrm{mM}$ palmitate for 3 days. The control cells cultured in high glucose $(25 \mathrm{mM})$ DMEM supplemented with $1 \%$ FBS were exposed to a vehicle containing the same amount of BSA as the BSA-conjugated palmitate solution.

\subsection{RNA Isolation, RT-PCR, and Sanger Sequencing}

Total RNA from pancreatic islets and $\beta$ TC6 cells was isolated using TRIzol reagent, followed by reverse transcription (RT) with Maxima reverse transcriptase following the manufacturer's protocol (Thermo Fisher Scientific). Specific primer sets (Table S1) were used for the PCR amplification of circRNAs and mRNAs using DreamTaq PCR Master Mix or PowerUp SYBR Green Master Mix, following the manufacturer's instructions. PCR was set up with a cycle set up of 2 min at $95^{\circ} \mathrm{C}$ followed by $35 / 40$ cycles of $95^{\circ} \mathrm{C}$ for $5 \mathrm{~s}, 60^{\circ} \mathrm{C}$ for $20 \mathrm{~s}$. RT-PCR products were resolved in SYBR-Gold-stained $2.5 \%$ agarose gels and visualized on an ultraviolet transilluminator. The RT-PCR products were purified and subjected to Sanger sequencing to check the specific amplification of the target circRNAs.

\subsection{PCR Product Cloning and DNA Sequencing}

RT-PCR products of $c i$-Ins2 amplified with divergent primers were gel-purified using the PureLink Quick Gel Extraction Kit (Thermo Fisher Scientific). The purified PCR products were cloned into pGEM $^{\circledR}$-T Easy Vector Systems (Promega) following the manufacturer's protocol. Individual positive 
clones were selected for culture, and plasmids were purified using the plasmid isolation kit (HiMedia). The sequences of the cloned PCR products were confirmed by Sanger sequencing of the plasmids with T7 primer.

\subsection{Quantitative (q)PCR Analysis and RNase R Treatment}

RT followed by quantitative PCR (RT-qPCR) analysis of target RNAs was performed using PowerUp SYBR Green Master Mix (Applied Biosystems) with specific primers (Table S1). RT-qPCR was performed on a QuantStudio 3/6 real-time PCR system (Thermo Fisher Scientific), and the relative RNA abundance was calculated using the delta-CT method. The circular nature of $c i$-Ins2 and other circRNAs was tested using an RNase R treatment assay. Total RNA from $\beta$ TC6 cells and islets was digested with $20 \mathrm{U}$ of RNase $\mathrm{R}$ (Epicentre) at $37^{\circ} \mathrm{C}$ for $30 \mathrm{~min}$, followed by RT-qPCR analysis, as described previously [57].

\subsection{Prediction of RBPs, miRNA, and $m R N A$ Targets}

The genomic sequences of ci-Ins2 (486nt) and Ins2 were retrieved from the UCSC genome browser (http://genome.ucsc.edu/). The RBPs associated with Ins2 pre-mRNA were identified with the beRBP tool using the default parameters [42]. The number of RBP binding sites on the specific regions of the Ins2 pre-mRNA is provided in Table S5. The miRNAs associated with ci-Ins2 (486 nt) were identified using the miRDB web server (http://mirdb.org; accessed on 12 January 2020) [45]. Target mRNAs of miRNAs associated with ci-Ins2 were identified using miRDB, RNA22, miRTarBase, and TargetScan software [45-48]. The differentially expressed mRNAs in islets of mice fed with HFD compared to ND were retrieved from the GEO data set (accession GSE92602) of the previous publication [33]. The mRNAs predicted by two or more software and differentially expressed in islets of mice fed with HFD compared to ND were selected for further analysis (Table S6). The Gene Ontology analysis for biological process, cellular component, and molecular function was performed, with a statistical overrepresentation test using Fisher's extract and Bonferroni correction using the Panther database (http://www.pantherdb.org/; accessed on 4 April 2020) [49]. The pathway enrichment analysis was performed using the Panther database [49].

\subsection{Statistical Analysis and Visualization}

CircRNAs with log2 fold-changes greater than 2 and p-values less than 0.01 between ND- and HFD-fed mice islets were considered as differentially expressed. All experiments were repeated at least 3 times and were represented as the mean \pm SEM. Comparison between control and treatment groups were analyzed with Student's $t$-test and $p<0.05$ was considered statistically significant. Heatmap for RBP binding sites and the differentially expressed circRNAs were generated in Excel and in R using ComplexHeatmap, respectively [58]. Graphs and plots were generated using Excel, GraphPad Prism, or ggplot2 package in $\mathrm{R}$.

\section{Conclusions}

In summary, we have identified a number of DE-circRNAs in the islets of mice fed with HFD compared to ND. Our data discovered the expression of multiple ci-Ins2 transcripts derived from intron 2 of the mouse Ins 2 gene. The ci-Ins 2 transcripts may act as a decoy for RBPs and/or miRNAs due to the presence of RBP- and miRNA-binding sites, respectively. However, future studies analyzing the interaction of RBPs and miRNAs with ci-Ins2 may uncover their role in $\beta$-cell physiology and the development of diabetes. As dysregulation of insulin biosynthesis is critical for the development of diabetes, interventions to modulate Ins 2 expression by regulating ci-Ins 2 function may be therapeutically valuable in the treatment of diabetes. Finally, a comprehensive understanding of the biogenesis and impact of $c$-Ins 2 on $\beta$-cell gene expression programs will offer new avenues to explore the significance of circRNAs on $\beta$-cell proliferation, insulin biosynthesis, and insulin secretion. 
Supplementary Materials: The following are available online at http://www.mdpi.com/1422-0067/21/12/4302/s1. Figure S1: Characteristics of circRNAs in mouse pancreatic islets. Figure S2: Selected list of circRNAs from RNA-seq data. Figure S3: Validation of circRNAs in $\beta$ TC6 cells. Figure S4: Validation of circular Ins2 transcripts in islets. Figure S5: Lariat branchpoint sequence of ci-Ins2_415. Figure S6: Sequence of ci-Ins2 transcripts. Table S1: List of oligos used for the study. Table S2: circRNA annotation by CIRCexplorer2. Table S3: circRNA annotation by CIRI2. Table S4: List of circRNAs derived from mouse Ins1 and Ins2 gene detected using CIRCexplorer2. Table S5: List of RBPs and the number of binding sites predicted in different regions of mouse Ins2 pre-mRNA using beRBP. Table S6: CircRNA-miRNA-mRNA regulatory network for ci-Ins2 (486 nt).

Author Contributions: Conceptualization, D.D. and A.C.P.; data curation, D.D., A.D. (Aniruddha Das), and A.C.P.; formal analysis, D.D., A.D. (Aniruddha Das), S.K., P.K.R., A.D. (Arundhati Das), G.P.M., S.K.R., A.D. (Anshuman Dixit), and A.C.P.; funding acquisition, A.C.P.; investigation, D.D., A.D. (Aniruddha Das), M.S., S.S.M., S.K., P.R.B., P.K.R., A.D. (Arundhati Das), S.B., and G.P.M.; methodology, D.D., A.D. (Aniruddha Das), M.S., S.S.M., S.K., P.R.B., P.K.R., A.D. (Arundhati Das), S.B., G.P.M., and A.C.P.; resources, S.B., S.K.R., A.D. (Anshuman Dixit), and A.C.P.; software, M.S., S.S.M., S.K., P.R.B., G.P.M., S.K.R., and A.D. (Anshuman Dixit); supervision, S.K.R., A.D. (Anshuman Dixit), and A.C.P.; validation, D.D., A.D. (Aniruddha Das), A.D. (Anshuman Dixit), and A.C.P.; visualization, M.S., S.S.M., S.K., and P.R.B.; writing-original draft, D.D., A.D. (Aniruddha Das), and A.C.P.; writing—review and editing, D.D., A.D. (Aniruddha Das), M.S., P.R.B., A.D. (Arundhati Das), G.P.M., S.K.R., A.D. (Anshuman Dixit), and A.C.P. All authors have read and agreed to the published version of the manuscript.

Funding: This research was supported by Wellcome Trust/DBT India Alliance Intermediate Fellowship to Amaresh Chandra Panda (grant number: IA/I/18/2/504017) and intramural funding from the Institute of Life Sciences, Department of Biotechnology, India. Debojyoti Das, Aniruddha Das, and Arundhati Das were supported by the Junior Research Fellowship from University Grant Commission, India. Smruti Sambhav Mishra and Pruthvi Raj Bejugam were supported by the Wellcome Trust/DBT India Alliance. The APC was funded by India Alliance IA/I/18/2/504017.

Acknowledgments: The authors thank Vasudevan Seshadri (NCCS, Pune) and Narottam Acharya (ILS, Bhubaneswar) for helpful discussions and suggestions during the study. Additionally, we gratefully thank Sarita Jena and the experimental animal facility at the Institute of Life Sciences.

Conflicts of Interest: The authors declare no conflict of interest.

\section{References}

1. Cho, N.H.; Shaw, J.E.; Karuranga, S.; Huang, Y.; da Rocha Fernandes, J.D.; Ohlrogge, A.W.; Malanda, B. IDF Diabetes atlas: Global estimates of diabetes prevalence for 2017 and projections for 2045. Diabetes Res. Clin. Pr. 2018, 138, 271-281. [CrossRef] [PubMed]

2. Harreiter, J.; Roden, M. Diabetes mellitus-definition, classification, diagnosis, screening and prevention. Wien. Klin. Wochenschr. 2019, 131, 6-15. [CrossRef] [PubMed]

3. Laville, M.; Nazare, J.A. Diabetes, insulin resistance and sugars. Obes. Rev. 2009, 10, 24-33. [CrossRef] [PubMed]

4. Plum, L.; Belgardt, B.F.; Bruning, J.C. Central insulin action in energy and glucose homeostasis. J. Clin. Invest. 2006, 116, 1761-1766. [CrossRef]

5. Melloul, D.; Marshak, S.; Cerasi, E. Regulation of insulin gene transcription. Diabetologia 2002, 45, 309-326. [CrossRef]

6. Panda, A.C.; Grammatikakis, I.; Yoon, J.H.; Abdelmohsen, K. Posttranscriptional regulation of insulin family ligands and receptors. Int. J. Mol. Sci. 2013, 14, 19202-19229. [CrossRef]

7. Evans-Molina, C.; Garmey, J.C.; Ketchum, R.; Brayman, K.L.; Deng, S.; Mirmira, R.G. Glucose regulation of insulin gene transcription and pre-mRNA processing in human islets. Diabetes 2007, 56, 827-835. [CrossRef]

8. Panda, A.C.; Sahu, I.; Kulkarni, S.D.; Martindale, J.L.; Abdelmohsen, K.; Vindu, A.; Joseph, J.; Gorospe, M.; Seshadri, V. miR-196b-mediated translation regulation of mouse insulin2 via the 5'UTR. PLoS ONE 2014, 9, e101084. [CrossRef]

9. Kulkarni, S.D.; Muralidharan, B.; Panda, A.C.; Bakthavachalu, B.; Vindu, A.; Seshadri, V. Glucose-stimulated translation regulation of insulin by the 5' UTR-binding proteins. J. Biol. Chem. 2011, 286, 14146-14156. [CrossRef]

10. Guria, A.; Sharma, P.; Natesan, S.; Pandi, G. Circular RNAs-the road less traveled. Front. Mol. Biosci. 2019, 6, 146. [CrossRef]

11. Ji, P.; Wu, W.; Chen, S.; Zheng, Y.; Zhou, L.; Zhang, J.; Cheng, H.; Yan, J.; Zhang, S.; Yang, P.; et al. Expanded expression landscape and prioritization of circular RNAs in mammals. Cell Rep. 2019, 26, 3444-3460. [CrossRef] [PubMed] 
12. Glazar, P.; Papavasileiou, P.; Rajewsky, N. circBase: A database for circular RNAs. RNA 2014, 20, 1666-1670. [CrossRef] [PubMed]

13. Vromman, M.; Vandesompele, J.; Volders, P.J. Closing the circle: Current state and perspectives of circular RNA databases. Brief. Bioinform. 2020. [CrossRef] [PubMed]

14. Zhang, X.O.; Dong, R.; Zhang, Y.; Zhang, J.L.; Luo, Z.; Zhang, J.; Chen, L.L.; Yang, L. Diverse alternative back-splicing and alternative splicing landscape of circular RNAs. Genome Res. 2016, 26, 1277-1287. [CrossRef] [PubMed]

15. Zhang, Y.; Xue, W.; Li, X.; Zhang, J.; Chen, S.; Zhang, J.L.; Yang, L.; Chen, L.L. The biogenesis of nascent circular RNAs. Cell Rep. 2016, 15, 611-624. [CrossRef] [PubMed]

16. Zhang, Y.; Zhang, X.O.; Chen, T.; Xiang, J.F.; Yin, Q.F.; Xing, Y.H.; Zhu, S.; Yang, L.; Chen, L.L. Circular intronic long noncoding RNAs. Mol. Cell. 2013, 51, 792-806. [CrossRef]

17. Panda, A.C.; De, S.; Grammatikakis, I.; Munk, R.; Yang, X.; Piao, Y.; Dudekula, D.B.; Abdelmohsen, K.; Gorospe, M. High-purity circular RNA isolation method (RPAD) reveals vast collection of intronic circRNAs. Nucleic Acids Res. 2017, 45, e116. [CrossRef]

18. Li, Z.; Huang, C.; Bao, C.; Chen, L.; Lin, M.; Wang, X.; Zhong, G.; Yu, B.; Hu, W.; Dai, L.; et al. Exon-intron circular RNAs regulate transcription in the nucleus. Nat. Struct. Mol. Biol. 2015, 22, 256-264. [CrossRef]

19. Jeck, W.R.; Sorrentino, J.A.; Wang, K.; Slevin, M.K.; Burd, C.E.; Liu, J.; Marzluff, W.F.; Sharpless, N.E. Circular RNAs are abundant, conserved, and associated with ALU repeats. RNA 2013, 19, 141-157. [CrossRef]

20. Memczak, S.; Jens, M.; Elefsinioti, A.; Torti, F.; Krueger, J.; Rybak, A.; Maier, L.; Mackowiak, S.D.; Gregersen, L.H.; Munschauer, M.; et al. Circular RNAs are a large class of animal RNAs with regulatory potency. Nature 2013, 495, 333-338. [CrossRef]

21. Pamudurti, N.R.; Bartok, O.; Jens, M.; Ashwal-Fluss, R.; Stottmeister, C.; Ruhe, L.; Hanan, M.; Wyler, E.; Perez-Hernandez, D.; Ramberger, E.; et al. Translation of CircRNAs. Mol. Cell 2017, 66, 9-21. [CrossRef] [PubMed]

22. Panda, A.C. Circular RNAs Act as miRNA sponges. Adv. Exp. Med. Biol. 2018, 1087, 67-79. [CrossRef] [PubMed]

23. Pandey, P.R.; Yang, J.H.; Tsitsipatis, D.; Panda, A.C.; Noh, J.H.; Kim, K.M.; Munk, R.; Nicholson, T.; Hanniford, D.; Argibay, D.; et al. circSamd4 represses myogenic transcriptional activity of PUR proteins. Nucleic Acids Res. 2020. [CrossRef] [PubMed]

24. Ashwal-Fluss, R.; Meyer, M.; Pamudurti, N.R.; Ivanov, A.; Bartok, O.; Hanan, M.; Evantal, N.; Memczak, S.; Rajewsky, N.; Kadener, S. circRNA biogenesis competes with pre-mRNA splicing. Mol. Cell 2014, 56, 55-66. [CrossRef] [PubMed]

25. Abdelmohsen, K.; Panda, A.C.; De, S.; Grammatikakis, I.; Kim, J.; Ding, J.; Noh, J.H.; Kim, K.M.; Mattison, J.A.; de Cabo, R.; et al. Circular RNAs in monkey muscle: Age-dependent changes. Aging 2015, 7, 903-910. [CrossRef]

26. Panda, A.C.; Grammatikakis, I.; Kim, K.M.; De, S.; Martindale, J.L.; Munk, R.; Yang, X.; Abdelmohsen, K.; Gorospe, M. Identification of senescence-associated circular RNAs (SAC-RNAs) reveals senescence suppressor CircPVT1. Nucleic Acids Res. 2017, 45, 4021-4035. [CrossRef]

27. Das, A.; Das, A.; Das, D.; Abdelmohsen, K.; Panda, A.C. Circular RNAs in myogenesis. Biochim. Biophys. Acta Gene Regul. Mech. 2019, 194372. [CrossRef]

28. Das, D.; Das, A.; Panda, A.C. Emerging role of long noncoding RNAs and circular RNAs in pancreatic $\beta$ cells. Non Coding RNA Investig. 2018, 2, 1-13. [CrossRef]

29. Haque, S.; Harries, L.W. Circular RNAs (circRNAs) in health and disease. Genes 2017, 8, 353. [CrossRef]

30. Li, J.; Sun, D.; Pu, W.; Wang, J.; Peng, Y. Circular RNAs in cancer: Biogenesis, function, and clinical significance. Trends Cancer 2020, 6, 319-336. [CrossRef]

31. Huang, J.L.; Xu, Z.H.; Yang, S.M.; Yu, C.; Zhang, F.; Qin, M.C.; Zhou, Y.; Zhong, Z.G.; Wu, D.P. Identification of differentially expressed profiles of Alzheimer's disease associated circular RNAs in a panax notoginseng saponins-treated Alzheimer's disease mouse model. Comput. Struct. Biotechnol. J. 2018, 16, 523-531. [CrossRef] [PubMed]

32. Stoll, L.; Sobel, J.; Rodriguez-Trejo, A.; Guay, C.; Lee, K.; Veno, M.T.; Kjems, J.; Laybutt, D.R.; Regazzi, R. Circular RNAs as novel regulators of beta-cell functions in normal and disease conditions. Mol. Metab. 2018, 9, 69-83. [CrossRef] [PubMed] 
33. Motterle, A.; Gattesco, S.; Peyot, M.L.; Esguerra, J.L.S.; Gomez-Ruiz, A.; Laybutt, D.R.; Gilon, P.; Burdet, F.; Ibberson, M.; Eliasson, L.; et al. Identification of islet-enriched long non-coding RNAs contributing to beta-cell failure in type 2 diabetes. Mol. Metab. 2017, 6, 1407-1418. [CrossRef] [PubMed]

34. Wu, W.; Ji, P.; Zhao, F. CircAtlas: An integrated resource of one million highly accurate circular RNAs from 1070 vertebrate transcriptomes. Genome Biol. 2020, 21, 101. [CrossRef]

35. Mercer, T.R.; Clark, M.B.; Andersen, S.B.; Brunck, M.E.; Haerty, W.; Crawford, J.; Taft, R.J.; Nielsen, L.K.; Dinger, M.E.; Mattick, J.S. Genome-wide discovery of human splicing branchpoints. Genome Res. 2015, 25, 290-303. [CrossRef]

36. Suzuki, H.; Zuo, Y.; Wang, J.; Zhang, M.Q.; Malhotra, A.; Mayeda, A. Characterization of RNase R-digested cellular RNA source that consists of lariat and circular RNAs from pre-mRNA splicing. Nucleic Acids Res. 2006, 34, e63. [CrossRef]

37. Pineda, J.M.B.; Bradley, R.K. Most human introns are recognized via multiple and tissue-specific branchpoints. Genes Dev. 2018, 32, 577-591. [CrossRef]

38. Kelpe, C.L.; Moore, P.C.; Parazzoli, S.D.; Wicksteed, B.; Rhodes, C.J.; Poitout, V. Palmitate inhibition of insulin gene expression is mediated at the transcriptional level via ceramide synthesis. J. Biol. Chem. 2003, 278, 30015-30021. [CrossRef]

39. Ritz-Laser, B.; Meda, P.; Constant, I.; Klages, N.; Charollais, A.; Morales, A.; Magnan, C.; Ktorza, A.; Philippe, J. Glucose-induced preproinsulin gene expression is inhibited by the free fatty acid palmitate. Endocrinology 1999, 140, 4005-4014. [CrossRef]

40. Briaud, I.; Harmon, J.S.; Kelpe, C.L.; Segu, V.B.; Poitout, V. Lipotoxicity of the pancreatic beta-cell is associated with glucose-dependent esterification of fatty acids into neutral lipids. Diabetes 2001, 50, 315-321. [CrossRef]

41. Jacqueminet, S.; Briaud, I.; Rouault, C.; Reach, G.; Poitout, V. Inhibition of insulin gene expression by long-term exposure of pancreatic beta cells to palmitate is dependent on the presence of a stimulatory glucose concentration. Metabolism 2000, 49, 532-536. [CrossRef]

42. Yu, H.; Wang, J.; Sheng, Q.; Liu, Q.; Shyr, Y. beRBP: Binding estimation for human RNA-binding proteins. Nucleic Acids Res. 2019, 47, e26. [CrossRef] [PubMed]

43. Tillmar, L.; Welsh, N. Hypoxia may increase rat insulin mRNA levels by promoting binding of the polypyrimidine tract-binding protein (PTB) to the pyrimidine-rich insulin mRNA 3'-untranslated region. Mol. Med. 2002, 8, 263-272. [CrossRef] [PubMed]

44. Araki, K.; Araki, A.; Honda, D.; Izumoto, T.; Hashizume, A.; Hijikata, Y.; Yamada, S.; Iguchi, Y.; Hara, A.; Ikumi, K.; et al. TDP-43 regulates early-phase insulin secretion via CaV1.2-mediated exocytosis in islets. J. Clin. Invest. 2019, 130, 3578-3593. [CrossRef]

45. Chen, Y.; Wang, X. miRDB: An online database for prediction of functional microRNA targets. Nucleic Acids Res. 2020, 48, D127-D131. [CrossRef]

46. Loher, P.; Rigoutsos, I. Interactive exploration of RNA22 microRNA target predictions. Bioinformatics 2012, 28, 3322-3323. [CrossRef]

47. Agarwal, V.; Bell, G.W.; Nam, J.W.; Bartel, D.P. Predicting effective microRNA target sites in mammalian mRNAs. Elife 2015, 4. [CrossRef]

48. Huang, H.Y.; Lin, Y.C.; Li, J.; Huang, K.Y.; Shrestha, S.; Hong, H.C.; Tang, Y.; Chen, Y.G.; Jin, C.N.; Yu, Y.; et al. miRTarBase 2020: Updates to the experimentally validated microRNA-target interaction database. Nucleic Acids Res. 2020, 48, D148-D154. [CrossRef]

49. Mi, H.; Muruganujan, A.; Ebert, D.; Huang, X.; Thomas, P.D. PANTHER version 14: More genomes, a new PANTHER GO-slim and improvements in enrichment analysis tools. Nucleic Acids Res. 2019, 47, D419-D426. [CrossRef]

50. Cerf, M.E. Beta cell dysfunction and insulin resistance. Front. Endocrinol. 2013, 4, 37. [CrossRef]

51. Erion, K.; Corkey, B.E. Beta-cell failure or beta-cell abuse? Front. Endocrinol. 2018, 9, 532. [CrossRef]

52. Hansen, T.B.; Jensen, T.I.; Clausen, B.H.; Bramsen, J.B.; Finsen, B.; Damgaard, C.K.; Kjems, J. Natural RNA circles function as efficient microRNA sponges. Nature 2013, 495, 384-388. [CrossRef] [PubMed]

53. Ivanov, A.; Memczak, S.; Wyler, E.; Torti, F.; Porath, H.T.; Orejuela, M.R.; Piechotta, M.; Levanon, E.Y.; Landthaler, M.; Dieterich, C.; et al. Analysis of intron sequences reveals hallmarks of circular RNA biogenesis in animals. Cell Rep. 2015, 10, 170-177. [CrossRef] [PubMed]

54. Gao, Y.; Zhang, J.; Zhao, F. Circular RNA identification based on multiple seed matching. Brief. Bioinform. 2018, 19, 803-810. [CrossRef] [PubMed] 
55. Robinson, M.D.; McCarthy, D.J.; Smyth, G.K. edgeR: A bioconductor package for differential expression analysis of digital gene expression data. Bioinformatics 2010, 26, 139-140. [CrossRef]

56. Panda, A.C.; Kulkarni, S.D.; Muralidharan, B.; Bakthavachalu, B.; Seshadri, V. Novel splice variant of mouse insulin2 mRNA: Implications for insulin expression. FEBS Lett. 2010, 584, 1169-1173. [CrossRef]

57. Panda, A.C.; Gorospe, M. Detection and analysis of circular RNAs by RT-PCR. Bio Protoc. 2018, 8. [CrossRef]

58. Gu, Z.; Eils, R.; Schlesner, M. Complex heatmaps reveal patterns and correlations in multidimensional genomic data. Bioinformatics 2016, 32, 2847-2849. [CrossRef]

(C) 2020 by the authors. Licensee MDPI, Basel, Switzerland. This article is an open access article distributed under the terms and conditions of the Creative Commons Attribution (CC BY) license (http://creativecommons.org/licenses/by/4.0/). 